\title{
BDP1 Variants I1264M and V1347M Significantly Associated with Clinical Outcomes of Pediatric Neuroblastoma Patients Imply a New Prognostic Biomarker: A 121-Patient Cancer Genome Study
}

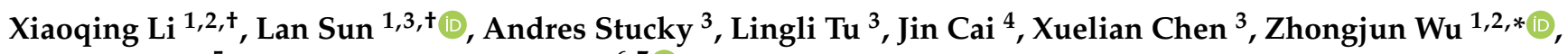 \\ Xuhong Jiang ${ }^{5, *}$ and Shengwen Calvin $\mathrm{Li}^{6,7}$ \\ 1 Department of Oncology, the People's Hospital of Bishan District, Chongqing 402760, China; \\ 2018020067@stu.cqmu.edu.cn (X.L.); 1s_000@usc.edu (L.S.) \\ 2 Department of Hepatobiliary Surgery, the First Affiliated Hospital of Chongqing Medical University, \\ Chongqing 400042, China \\ 3 Department of Otolaryngology, Keck School of Medicine, University of Southern California, \\ Los Angeles, CA 90033, USA; astucky@usc.edu (A.S.); tulingli425@gmail.com (L.T.); xuelianc@usc.edu (X.C.) \\ 4 Department of Oral and Maxillofacial Surgery, Zhuhai People's Hospital, Zhuhai Hospital Affiliated with \\ Jinan University, Zhuhai 519000, China; caijin70@163.com \\ check for \\ updates \\ Citation: Li, X.; Sun, L.; Stucky, A.; \\ Tu, L.; Cai, J.; Chen, X.; Wu, Z.; Jiang, \\ X.; Li, S.C. BDP1 Variants I1264M and \\ V1347M Significantly Associated with \\ Clinical Outcomes of Pediatric \\ Neuroblastoma Patients Imply a New \\ 5 Department of Health Management, Zhuhai People's Hospital, Zhuhai Hospital Affiliated with Jinan \\ University, Zhuhai 519000, China \\ 6 Neuro-Oncology and Stem Cell Research Laboratory, Center for Neuroscience Research, CHOC Children's \\ Research Institute, Children's Hospital of Orange County (CHOC), 1201 West La Veta Ave, \\ Orange, CA 92868-3874, USA; shengwel@uci.edu \\ 7 Department of Neurology, Irvine School of Medicine, University of California, 200 S Manchester Ave Ste 206, \\ Orange, CA 92868, USA \\ * Correspondence: wzjtcy@126.com (Z.W.); srmyyjkglk@zhuhai.gov.cn (X.J.) \\ + These authors contributed equally.
} Prognostic Biomarker: A 121-Patient Cancer Genome Study. Diagnostics 2021, 11, 2364. https://doi.org/ 10.3390/diagnostics11122364

\section{Academic Editors:}

Gustavo Baldassarre and Dario Marchetti

Received: 16 October 2021 Accepted: 29 November 2021 Published: 15 December 2021

Publisher's Note: MDPI stays neutral with regard to jurisdictional claims in published maps and institutional affiliations.

Copyright: $\odot 2021$ by the authors. Licensee MDPI, Basel, Switzerland. This article is an open access article distributed under the terms and conditions of the Creative Commons Attribution (CC BY) license (https:// creativecommons.org/licenses/by/ $4.0 /)$.
Abstract: Background: Neuroblastoma (N.B.) is the most common tumor in children. The gene BDP1 (B Double Prime 1) plays a role in cancers but is less known in N.B. Thus, we conducted this study to investigate the value of BDP1 mutations in N.B. prognosis. Methods: A dataset of 121 NB patients from the Cancer Genome Atlas database was used to analyze BDP1 gene mutations by RNA sequencing. Kaplan-Meier estimates were performed for overall survival (O.S.) analysis on BDP1 variants, and Cox's proportional hazards regression model was used for multivariate analysis. Results: In $121 \mathrm{NB}$ patients, we identified two variants of BDP1 associated with N.B., located at chr5:71511131 and chr5:71510884. The prevalence of these BDP1 variants, I1264M and V1347M, was $52.9 \%(64 / 121)$ and $45.5 \%(55 / 121)$, respectively. O.S. analysis showed a significant difference between subgroups with or without BDP1 variants $(p<0.05)$. Multivariate analysis further revealed that BDP1ariants were independent prognostic variables in N.B. $(p<0.05)$. Conclusion: Our results suggest $B D P 1$ variants are associated with significantly improved clinical outcomes in N.B., thus providing clinicians with a new tool.

Keywords: $B D P 1$; variant; neuroblastoma; prognostic biomarker; prognosis

\section{Introduction}

As the most common extracranial pediatric solid tumor, ever since defined as an embryonal tumor of the autonomic nervous system, $90 \%$ of neuroblastoma (N.B.) cases are diagnosed before the patient is 5-year old, with a median age at diagnosis of around 18 months [1]. Such a delayed diagnosis results in patients with high-risk N.B. who come below 50\% for 5-year survival rates [2], especially in older children, with poor outcomes despite aggressive multimodal therapy [2]. This situation sparks the International Neuroblastoma Risk Group (INRG) to standardize diagnostic systems using age, histology, 
stage, tumor grade, and genomic factors. The genomic factors include DNA ploidy, MYCN $(\mathrm{n}-\mathrm{myc})$ status, somatic and germline mutations, as determined by whole-exome, wholegenome [3], Whole-transcriptome sequencing (WTS, also known as RNA-seq) [4], to define high-risk N.B. age and signature-associated driver alterations. The long non-coding RNA MIAT (myocardial infarction associated transcript) regulating neuroblastoma and glioblastoma cell fate [5] acts as an oncogene, potentially predictive, and prognostic biomarker. Some base excision repair pathway variants tighten N.B. susceptibility into a population of eastern Chinese children [6]. Following that, an eight-center case-control study of 898 cases and 1734 controls reveals the single-nucleotide polymorphisms (SNPs) in the METTL14 gene could predispose to N.B. susceptibility [7]. Specifically, the associations with increased N.B. susceptibility for rs $9884978 \mathrm{G}>\mathrm{A}$ and $\mathrm{rs} 4834698 \mathrm{~T}>\mathrm{C}$, the protective effect of rs298982 $\mathrm{G}>\mathrm{A}$ and rs62328061 $\mathrm{A}>\mathrm{G}$, as well as the predisposing effect of $\mathrm{rs} 4834698 \mathrm{~T}>\mathrm{C}$ are found in specific subgroups. Similar functional polymorphisms manifested at ERCC1/XPF genes [8]. Ongoing efforts search for spatiotemporally-expressed biomarkers at the transcriptomic and protein expression level, aimed at diagnosis subtyping of neural-crest-derived malignancy before birth or in early childhood to avoid the metastatic dissemination [9]. These transcriptomic and protein expression patterns might define the genetic, morphological, and clinical heterogeneity. Such a combination of cellular phenotypes and molecular profiles sets up the frameworks of tumor functional context, i.e., tumor microenvironment [10] such tumor tissue elasticity [11].

Along the line, we focus on the human gene BDP1 (B Double Prime 1), located on chromosome 5q13, encodes a subunit of RNA Polymerase III Transcription Initiation Factor IIIB (TFIIIB) [12], which is suppressed by BRCA1 [13]. However, neither the BDP1's physiology nor its pathology in humans is fully known, unlike Drosophila melanogaster [14,15]. The manuscript attempted to energize the novelty of $B D P 1$ in N.B., even though the concept of $B D P 1$ 's cancer-involved is emerging with colorectal cancers [16,17], lung cancer [18], and breast cancer [19]. To date, the importance of BDP1 mutations in N.B. has remained relatively unstudied. Thus, we conducted this study to explore the value of BDP1 mutations in N.B. by RNA-seq, yielding a new perspective on a pediatric brain tumor N.B.

\section{Methods}

\subsection{Dataset}

A dataset representing $121 \mathrm{NB}$ patients was extracted from The Cancer Genome Atlas (TCGA) database (https:/ / www.genome.gov/Funded-Programs-Projects/CancerGenome-Atlas, assessed on 6 October 2020) -The Cancer Genome Atlas (TCGA) was a joint effort of the United States National Cancer Institute (NCI) and the US National Human Genome Research Institute (NHGRI). The Cancer Genome Atlas (TCGA), a landmark cancer genomics program, molecularly characterized over 20,000 primary cancer and matched normal samples spanning 33 cancer types (https: / / www.cancer.gov / about-nci/ organization/ccg/research/structural-genomics/tcga, accessed on 6 October 2020).These patients all completed a long-term clinical observation period from three months to ten years past diagnosis. We downloaded RNA-seq data on these tumor samples to conduct a risk analysis of the death of N.B. patients.

\subsection{Variant Calling for Detecting BDP1 Variants}

We followed the standard variant calling process of GATK ([20] (GATK website www.broadinstitute.org/gatk, accessed on 6 October 2020, for each patient's RNA-seq data, followed by variant annotation and detection of unique genes/variants in N.B. First, according to the variant calling of GATK, we used Picard to make a duplicate and then used GATK to split reads into exon samples. After that, we ran base recalibration according to the common SNPs and indels. Then, we used the HaplotypeCaller tool in GATK to call variants and filter variants with criteria of D.P. $>10$, Q.D. $<2$, F.S. $>30$, and no SNPcluster. The filters automatically applied by HaplotypeCaller built-in tools of evaluation metrics came with the abbreviations defined as the depth of informative coverage for each sample (D.P.), 
false-positive (F.P.), FisherStrand (F.S.), QualByDepth (Q.D.), true positive (T.P.). We used AnnoVar [21] for BDP1 variant annotations and only analyzed exonic variants. To study the BDP1 gene, we generated gene-sample and variant-sample matrices for the 121 samples. Each row represented a sample in the gene-sample matrix. Each column represented a gene from the set (the set of genes of filtered exonic variants). If BDP1 had exonic variants in a sample, the corresponding cell was assigned the value 1 (or otherwise 0 ). Each row represented a sample for the variant-sample matrix, and each column represented a gene variant. Similar to the gene-sample matrix, if a BDP1 variant occurred in a sample, the corresponding cell was assigned the value 1 . Otherwise, it was assigned 0.

\subsection{Statistical Analysis}

Overall survival (O.S.) was defined as the time from diagnosis to disease-related death or the date of the last follow-up. For O.S. calculation, patients alive at the end of the study period died from other causes or lost to follow-up were excluded in the Kaplan-Meier analyses and compared using the log-rank test. Cox's proportional hazards regression model was used for multivariate analysis.

\section{Results}

\subsection{BDP1 Variants Found in 121 NB Patients}

To tie in the clinical relevance, we investigated $121 \mathrm{NB}$ patients to search for the prevalence rate of BDP1 variants, I1264M and V1347M, showing 52.9\% (64/121) and 45.5\% (55/121), respectively. Notably, the rate of non-BDP1 variants was $44.6 \%(54 / 121)$, while the percentage of patients harboring both was $43.0 \%$ (52/121). We followed up with characteristics for correlation of these variants with the clinical outcomes.

\subsection{Clinical Outcomes of N.B. Patients Carrying BDP1 Variants}

We compared the clinical outcome in subgroups with specific variant patterns, biological markers, and clinical characteristics, including MYCN-amplification, age, gender, stage, Children's Oncology Group (COG) risk score, and grade in this large, independent population (Table 1). Specifically, we found two variants in BDP1, I1264M and V1347M, significantly associated with improved clinical outcomes (Figure 1). The median O.S. of the patients without I1264M was 35.8 months, and those without V1347M, considerably shorter than the median O.S. of those patients with variant I1264M (87.9 months, $p=0.0007$ ) or patients with V1347M (87.9 months, $p=0.0019)$.

Table 1. Clinical characteristics and variant patterns in NB population $(n=121)$.

\begin{tabular}{|c|c|c|c|}
\hline \multirow[b]{2}{*}{ Characteristics } & \multirow{2}{*}{$\begin{array}{c}\text { Patients } \\
\mathrm{n}=121(\%)\end{array}$} & \multicolumn{2}{|c|}{ Overall Survival } \\
\hline & & Median OS (months) & $p$ Value \\
\hline \multicolumn{4}{|l|}{ Gender } \\
\hline Male & $71(58.7)$ & 56.4 & 0.816 \\
\hline Female & $50(41.3)$ & 58.1 & \\
\hline \multicolumn{4}{|l|}{ Race } \\
\hline White & 87 (71.9) & 58.1 & \multirow{3}{*}{0.538} \\
\hline Black & $19(15.7)$ & 56.4 & \\
\hline Others & $15(12.4)$ & 56.5 & \\
\hline \multicolumn{4}{|l|}{ Location } \\
\hline Abdomen & $106(87.6)$ & 56.5 & \multirow[t]{2}{*}{0.604} \\
\hline Non-abdomen & $15(12.4)$ & 61.2 & \\
\hline \multicolumn{4}{|l|}{ Grade } \\
\hline Poorly differentiated & $94(77.7)$ & 79.5 & \multirow{3}{*}{0.573} \\
\hline Not poorly & $7(5.8)$ & 40.4 & \\
\hline Unknown & $20(16.5)$ & 37.1 & \\
\hline \multicolumn{4}{|l|}{ Ploidy } \\
\hline Diploid & $50(41.3)$ & 36.7 & \multirow[t]{2}{*}{$0.008^{*}$} \\
\hline Hyperdiploid & $71(58.7)$ & 81.1 & \\
\hline \multicolumn{4}{|l|}{ MYCN status } \\
\hline amplified & $26(21.5)$ & 33.8 & \multirow{2}{*}{0.248} \\
\hline non-amplified & 95 (78.5) & 58.8 & \\
\hline
\end{tabular}


Table 1. Cont.

\begin{tabular}{|c|c|c|c|}
\hline \multirow[b]{2}{*}{ Characteristics } & \multirow{2}{*}{$\begin{array}{c}\text { Patients } \\
\mathrm{n}=121(\%)\end{array}$} & \multicolumn{2}{|c|}{ Overall Survival } \\
\hline & & Median OS (months) & $p$ Value \\
\hline \multicolumn{4}{|l|}{ Age at diagnosis } \\
\hline$<18$ months & $20(16.5)$ & NA & $<0.001$ * \\
\hline$\geq 18$ months & $101(83.5)$ & 44.0 & \\
\hline \multicolumn{4}{|l|}{ Stage } \\
\hline 4 & $100(82.6)$ & 46.1 & $<0.001$ * \\
\hline Not 4 & $21(17.4)$ & NA & \\
\hline \multicolumn{4}{|l|}{ COG Risk } \\
\hline High risk & $103(85.1)$ & 46.1 & $<0.001^{*}$ \\
\hline Not high risk & $18(14.9)$ & NA & \\
\hline \multicolumn{4}{|l|}{ BDP1 } \\
\hline Non- I1264M & $57(47.1)$ & 35.8 & $<0.001$ * \\
\hline $\mathrm{I} 1264 \mathrm{M}$ & $64(52.9)$ & 87.9 & \\
\hline \multicolumn{4}{|l|}{ BDP1 } \\
\hline Non- V1347M & $66(54.5)$ & 35.8 & $0.002 *$ \\
\hline V1347M & $55(45.5)$ & 87.9 & \\
\hline
\end{tabular}

* Variables were statistically significant by Kaplan-Meier estimates using the log-rank test. NA: Not applicable.

a
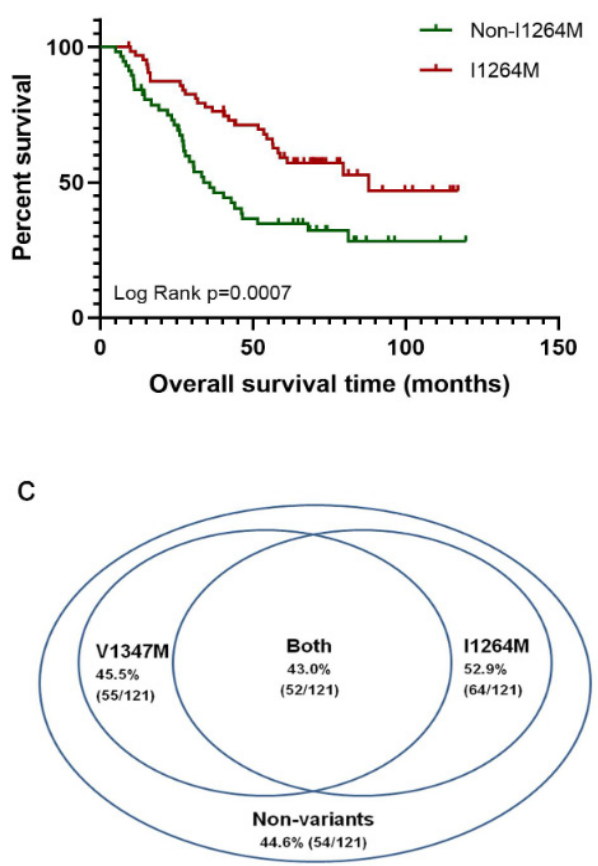

b

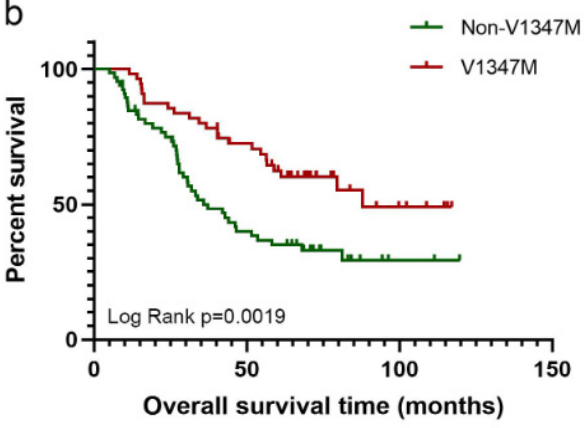

d

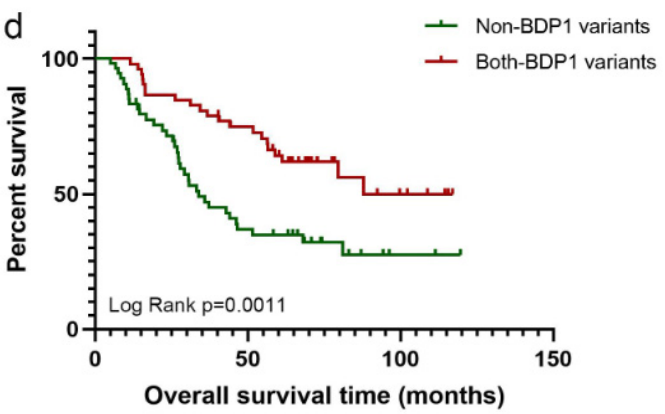

Figure 1. Association of two variants of BDP1, I1264M, and V1347M, with clinical outcomes in 121 pediatric neuroblastoma patients. Kaplan-Meier overall survival (O.S.) curves for $121 \mathrm{NB}$ patients according to their BDP1 variant status. Red and green indicate variant and non-variant, respectively. Two variants of BDP1, I1264M (a) and V1347M (b), significantly improved the overall survival time. Notably, the percentage of patients without BDP1 variants was $44.6 \%$, while $43.0 \%$ of patients harbored both (c). There was a significant difference in O.S. between them as well (d).

Table 1 suggests that I1264M alone has a dynamic prognostic value. Moreover, the median O.S. of the subset with non-BDP1 variants was 33.8 months, much shorter than the median O.S. of the subset harboring both BDP1 variants (87.9 months, $p=0.0011)$.

\subsection{BDP1 Variants May Serve for Neuroblastoma Prognosis}

We conducted a multivariate Cox hazard analysis of risk factors for N.B. prognosis (Table 2). As expected, stage, ploidy, and age at diagnosis were independent variables significantly associated with O.S. time; BDP1 variants V1347M and I1264M reduced patients' risk of death. Noteworthy, BDP1 variants V1347M and I1264M reduced patients' risk of 
death, and the hazard ratios (H.R.) for these variants were 0.488 (95\% confidence interval (CI): $0.289-0.826, p=0.007)$ and 0.58 (95\% CI: $0.349-0.964, p=0.035)$, respectively.

Table 2. Multivariate Cox hazard analysis of risk factors for prognosis.

\begin{tabular}{|c|c|c|c|}
\hline Characteristics & HR & $95 \%$ CI & $p$ Value \\
\hline $\begin{array}{l}\text { Ploidy } \\
\text { Hyperdiploid } \\
\text { Diploid }\end{array}$ & $\begin{array}{c}0.526 \\
1.0 \text { (Ref) }\end{array}$ & $0.317-0.872$ & 0.013 \\
\hline $\begin{array}{c}\text { MYCN status } \\
\text { amplified } \\
\text { non-amplified }\end{array}$ & $\begin{array}{c}0.986 \\
1.0 \text { (Ref) }\end{array}$ & $0.531-1.829$ & 0.963 \\
\hline $\begin{array}{l}\text { Age at diagnosis } \\
\geq 18 \text { months } \\
\quad<18 \text { months }\end{array}$ & $\begin{array}{c}20.692 \\
1.0 \text { (Ref) }\end{array}$ & $1.13-380.07$ & 0.041 \\
\hline $\begin{array}{c}\text { Stage } \\
\text { Not } 4 \\
4\end{array}$ & $\begin{array}{c}0.148 \\
1.0 \text { (Ref) }\end{array}$ & $0.03-0.729$ & 0.019 \\
\hline $\begin{array}{c}\text { COG Risk } \\
\text { High risk } \\
\text { Not high risk } \\
\text { BDP1 }\end{array}$ & $\begin{array}{c}6.824 \\
1.0 \text { (Ref) }\end{array}$ & $0.319-145.76$ & 0.219 \\
\hline $\begin{array}{c}\text { I1264M } \\
\text { Non- I1264M } \\
\text { BDP1 }\end{array}$ & $\begin{array}{c}0.580 \\
1.0 \text { (Ref) }\end{array}$ & $0.349-0.964$ & 0.035 \\
\hline $\begin{array}{c}\text { V1347M } \\
\text { Non-V1347M }\end{array}$ & $\begin{array}{c}0.488 \\
1.0 \text { (Ref) }\end{array}$ & $0.289-0.826$ & 0.007 \\
\hline
\end{tabular}

Abbreviations: HR, Hazard Ratio; CI, confidence interval.

\section{Discussion}

We provide valuable clinical data on a pediatric brain N.B. Specifically, we found that BDP1 variants, I1264M, V1347M, are associated with clinical outcomes, as measured by Kaplan-Meier overall survival (O.S.) curves, extrapolated from 121 patients of the TCGA data. The high-level amplification of $M Y C N$ on chromosome 2 p24 occurs in approximately $20 \%$ of N.B. patients, indicating its link to aggressive disease with a poor prognosis. Inhibitors that downregulate $M Y C N / M Y C$ proteins can suppress N.B. tumor growth [22]. Mutations in the tyrosine kinase domain of Anaplastic lymphoma kinase $(A L K)$ have also been identified in N.B. FDA approved a series of $A L K$ tyrosine kinase inhibitors (TKIs) for use in ALK-driven cancers [23]. Furthermore, the paired-like homeobox 2B gene (PHOX2B) was discovered as the first N.B. predisposition gene, accounting for $6.4 \%$ of heritable cases [24]. Despite the development of molecular strategies, the diagnostic and prognostic value of many gene mutations in N.B. patients is not very clear. Here, we first report the association of $B D P 1$ mutations with N.B. prognosis, showing that two BDP1 variants, I1264M and V1347M, are located at chr5:71510884 and chr5:71511131, are significantly correlated with better outcomes in an independent N.B. population. We further verified the prevalence of these BDP1 variants, I1264M and V1347M, were $52.9 \%(64 / 121)$ and $45.5 \%$ (55/121), respectively. Interestingly, the rate of patients harboring both was $43.0 \%(52 / 121)$, suggesting a high rate of overlap between them. Consistently, the minor allele frequency (MAF) of BDP1 polymorphism variants in an NCBI database were detected by DNA-seq ranging from $17 \%$ to $22 \%$, which was similar to our results using RNA-seq.

The weakness of the current approach was to make a comparison by evaluating the survival on the ground of gene expression on a single gene, which might be uninformative, given the fact that the variables that affect the clinical course of these patients are many and deserve an evaluation on a case history with clinical data collected (retrospective or prospective). However, the lack of such case history with clinical data collected (retrospective or prospective) is evident in the N.B.-databases. The solution to this problem might fall on conducting the work on registries in the future, which may be useful on gene expression 
studies but not on the outcome of the study only. Artificial intelligence-based medicine such as machine learning [25] might integrate case history, clinical information, molecular pathology, whole-genome sequencing, RNA seq., lifestyle courses, treatment-driven pathophysiological, and biomarker changes into comprehensive lifetime management. In previous reports, mutations in genes such as $A L K$ or $A T R X$ are associated with poor prognosis in N.B. [5]. In contrast, others, such as TAM1 variants, were associated with improved clinical outcomes [22]. Gene polymorphisms also confer N.B. susceptibility resulting in different clinical outcomes such as METTL14 [7] and ERCC1/XPF [8]. In our study, age at diagnosis ( $\geq 18$ months), diploidy, and stage IV were all associated with poor prognosis, as expected. Interestingly, both $B D P 1$ variants significantly improved overall survival time and reduced patients' risk of death from N.B. Therefore, our findings support that the protective phenotype of $B D P 1$ variants may exist in subsets of N.B. patients with the following implications.

First, establishing the association of BDP1 variants with clinical outcomes warrants in vitro or in vivo experimental verifications. Second, new bioinformatic methodologies may be used to explore the networks of these variants with accuracy. Third, both variants may affect BPD1 mRNA expression levels in subsets of N.B. patients [26]. Fourth, NB heterogeneity surfaces as single-cell characterization of malignant phenotypes and developmental trajectories of adrenal N.B. [27] for subclonal evolution [28]. Lastly, we must expand to explore the mechanisms by which these two variants affect the functions of NB-involved BDP1 (Figure 2). Thus, the value of BDP1 mutations in N.B. deserves further investigation.

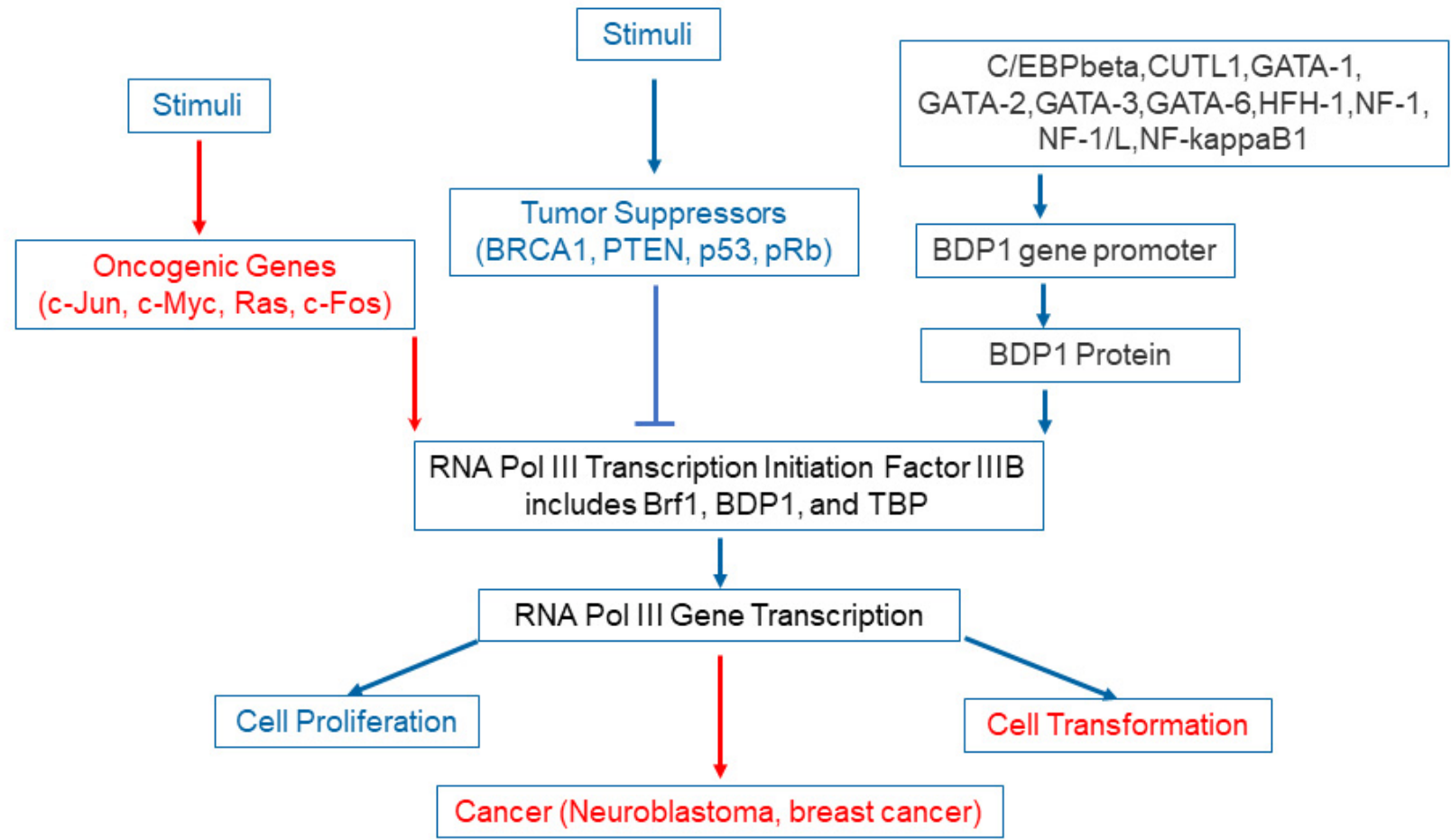

Figure 2. Role of BDP1 in the TFIIIB complex of transcription machinery in cell proliferation, cell transformation, and cancer progression. TFIIIB is a complex of the transcription machinery of RNA Pol III gene transcription [12]. TFIIIB consists of Brf1, BDP1, and TBP. Oncogenic proteins, such as c-Jun, c-Myc, Ras, and c-Fos activate TFIIIB to enhance RNA Pol III gene transcription, resulting in cancer tumorigenesis, while tumor suppressors, such as $B R C A 1$ [13], PTEN, $p 53$, and $p R b$, inactivate its activity to decrease the transcription of Pol III genes [14], leading to repression of tumor development [BDP1, a.k.a., TATA Box Binding Protein (TBP)-Associated Factor] [16]. TFIIIB). The concept of BDP1's cancer-involved is emerging with colorectal cancers [16,17], lung cancer [18], and breast cancer [19]. 
Author Contributions: X.J., Z.W. and J.C. conceived of the study. X.L., L.S. and S.C.L. drafted the manuscript. A.S., L.T. and X.C. performed the data analysis. All other authors participated in its experimentation and revision of the manuscript. All authors have read and agreed to the published version of the manuscript.

Funding: This study was supported by the Natural Science Foundation of Chongqing, China (cstc2020jcyj-msxmX1063), graduate tutor team construction project of Chongqing Municipal Education Commission Foundation, China (dstd201801), and National Natural Science Foundation of China (81703063). This work was also supported in part by the CHOC Children's-UC Irvine Child Health Research Awards \#16004004; CHOC-UCI Child Health Research grant \#16004003; and CHOC CSO grant \#16986004.

Institutional Review Board Statement: Not applicable.

Informed Consent Statement: Not applicable. Patient consent was waived for the NIH public databases (The Cancer Genome Atlas).

Data Availability Statement: Publicly available datasets were analyzed in this study. This data can be found here: https:/ / portal.gdc.cancer.gov.

Conflicts of Interest: The authors declare that they have no competing interest. The funders had no role in the design of the study; in the collection, analyses, or interpretation of data; in the writing of the manuscript, or in the decision to publish the results.

\section{References}

1. Morandi, F.; Sabatini, F.; Podesta, M.; Airoldi, I. Immunotherapeutic Strategies for Neuroblastoma: Present, Past and Future. Vaccines 2021, 9, 43. [CrossRef]

2. $\quad$ London, W.B.; Castleberry, R.P.; Matthay, K.K.; Look, A.T.; Seeger, R.C.; Shimada, H.; Thorner, P.; Brodeur, G.; Maris, J.M.; Reynolds, C.P.; et al. Evidence for an age cutoff greater than 365 days for neuroblastoma risk group stratification in the Children's Oncology Group. J. Clin. Oncol. 2005, 23, 6459-6465. [CrossRef] [PubMed]

3. Pugh, T.J.; Morozova, O.; Attiyeh, E.F.; Asgharzadeh, S.; Wei, J.S.; Auclair, D.; Carter, S.L.; Cibulskis, K.; Hanna, M.; Kiezun, A.; et al. The genetic landscape of high-risk neuroblastoma. Nat. Genet. 2013, 45, 279-284. [CrossRef] [PubMed]

4. Brady, S.W.; Liu, Y.; Ma, X.; Gout, A.M.; Hagiwara, K.; Zhou, X.; Wang, J.; Macias, M.; Chen, X.; Easton, J.; et al. Pan-neuroblastoma analysis reveals age- and signature-associated driver alterations. Nat. Commun. 2020, 11, 5183. [CrossRef]

5. Bountali, A.; Tonge, D.P.; Mourtada-Maarabouni, M. RNA sequencing reveals a key role for the long non-coding RNA MIAT in regulating neuroblastoma and glioblastoma cell fate. Int. J. Biol. Macromol. 2019, 130, 878-891. [CrossRef]

6. Zhuo, Z.; Zhou, C.; Fang, Y.; Zhu, J.; Lu, H.; Zhou, H.; Wu, H.; Wang, Y.; He, J. Correlation between the genetic variants of base excision repair (BER) pathway genes and neuroblastoma susceptibility in eastern Chinese children. Cancer Commun. (Lond.) 2020, 40, 641-646. [CrossRef] [PubMed]

7. Zhuo, Z.; Lu, H.; Zhu, J.; Hua, R.X.; Li, Y.; Yang, Z.; Zhang, J.; Cheng, J.; Zhou, H.; Li, S.; et al. METTL14 Gene Polymorphisms Confer Neuroblastoma Susceptibility: An Eight-Center Case-Control Study. Mol. Ther. Nucleic Acids 2020, 22, 17-26. [CrossRef]

8. Zhuo, Z.J.; Liu, W.; Zhang, J.; Zhu, J.; Zhang, R.; Tang, J.; Yang, T.; Zou, Y.; He, J.; Xia, H. Functional Polymorphisms at ERCC1/XPF Genes Confer Neuroblastoma Risk in Chinese Children. EBioMedicine 2018, 30, 113-119. [CrossRef]

9. Li, S.C.; Kabeer, M.H. Spatiotemporal switching signals for cancer stem cell activation in pediatric origins of adulthood cancer: Towards a watch-and-wait lifetime strategy for cancer treatment. World J. Stem Cells 2018, 10, 15-22. [CrossRef]

10. Nolan, J.C.; Salvucci, M.; Carberry, S.; Barat, A.; Segura, M.F.; Fenn, J.; Prehn, J.H.M.; Stallings, R.L.; Piskareva, O. A ContextDependent Role for MiR-124-3p on Cell Phenotype, Viability and Chemosensitivity in Neuroblastoma in vitro. Front. Cell. Dev. Biol. 2020, 8, 559553. [CrossRef] [PubMed]

11. Vu, L.T.; Keschrumrus, V.; Zhang, X.; Zhong, J.F.; Su, Q.; Kabeer, M.H.; Loudon, W.G.; Li, S.C. Tissue elasticity regulated tumor gene expression: Implication for diagnostic biomarkers of primitive neuroectodermal tumor. PLoS ONE 2015, 10, e0120336. [CrossRef]

12. Schoenen, F.; Wirth, B. The zinc finger protein ZNF297B interacts with BDP1, a subunit of TFIIIB. Biol. Chem. 2006, 387, 277-284. [CrossRef]

13. Veras, I.; Rosen, E.M.; Schramm, L. Inhibition of RNA polymerase III transcription by BRCA. J. Mol. Biol. 2009, 387, 523-531. [CrossRef]

14. Kim, M.K.; Tranvo, A.; Hurlburt, A.M.; Verma, N.; Phan, P.; Luo, J.; Ranish, J.; Stumph, W.E. Assembly of SNAPc, Bdp1, and TBP on the U6 snRNA Gene Promoter in Drosophila melanogaster. Mol. Cell. Biol. 2020, 40, e00641-19. [CrossRef] [PubMed]

15. Verma, N.; Hurlburt, A.M.; Wolfe, A.; Kim, M.K.; Kang, Y.S.; Kang, J.J.; Stumph, W.E. Bdp1 interacts with SNAPc bound to a U6, but not U1, snRNA gene promoter element to establish a stable protein-DNA complex. FEBS Lett. 2018, 592, 2489-2498. [CrossRef] [PubMed] 
16. Son, H.J.; Mo, H.Y.; Yoo, N.J.; Lee, S.H. Somatic mutations of cancer-related genes PELP1 and BDP1 in colorectal cancers. Pathol. Res. Pract. 2020, 216, 153107. [CrossRef]

17. Gouge, J.; Guthertz, N.; Kramm, K.; Dergai, O.; Abascal-Palacios, G.; Satia, K.; Cousin, P.; Hernandez, N.; Grohmann, D.; Vannini, A. Molecular mechanisms of Bdp1 in TFIIIB assembly and RNA polymerase III transcription initiation. Nat. Commun. 2017, 8, 130. [CrossRef]

18. Zhou, W.; Bai, C.; Long, C.; Hu, L.; Zheng, Y. Construction and Characterization of Long Non-Coding RNA-Associated Networks to Reveal Potential Prognostic Biomarkers in Human Lung Adenocarcinoma. Front. Oncol. 2021, 11, 720400. [CrossRef]

19. Gensler, M.; Buschbeck, M.; Ullrich, A. Negative regulation of HER2 signaling by the PEST-type protein-tyrosine phosphatase BDP1. J. Biol. Chem. 2004, 279, 12110-12116. [CrossRef]

20. Poplin, R.; Ruano-Rubio, V.; DePristo, M.A.; Fennell, T.J.; Carneiro, M.O.; Van der Auwera, G.A.; Kling, D.E.; Gauthier, L.D.; Levy-Moonshine, A.; Roazen, D.; et al. Scaling accurate genetic variant discovery to tens of thousands of samples. bioRxiv 2018, 201178. [CrossRef]

21. Wang, K.; Li, M.; Hakonarson, H. ANNOVAR: Functional annotation of genetic variants from high-throughput sequencing data. Nucleic Acids Res. 2010, 38, e164. [CrossRef] [PubMed]

22. Taylor, J.S.; Zeki, J.; Ornell, K.; Coburn, J.; Shimada, H.; Ikegaki, N.; Chiu, B. Down-regulation of MYCN protein by CX-5461 leads to neuroblastoma tumor growth suppression. J. Pediatr. Surg. 2019, 54, 1192-1197. [CrossRef] [PubMed]

23. Umapathy, G.; Mendoza-Garcia, P.; Hallberg, B.; Palmer, R.H. Targeting anaplastic lymphoma kinase in neuroblastoma. APMIS 2019, 127, 288-302. [CrossRef]

24. Raabe, E.H.; Laudenslager, M.; Winter, C.; Wasserman, N.; Cole, K.; LaQuaglia, M.; Maris, D.J.; Mosse, Y.P.; Maris, J.M. Prevalence and functional consequence of PHOX2B mutations in neuroblastoma. Oncogene 2008, 27, 469-476. [CrossRef] [PubMed]

25. Zhang, J.; Su, Q.; Loudon, W.G.; Lee, K.L.; Luo, J.; Dethlefs, B.A.; Li, S.C. Breathing Signature as Vitality Score Index Created by Exercises of Qigong: Implications of Artificial Intelligence Tools Used in Traditional Chinese Medicine. J. Funct. Morphol. Kinesiol. 2019, 4, 71. [CrossRef]

26. Sun, L.; Stucky, A.; Tu, L.; Chen, X.; Luo, J.; Zhong, J.F. FAM120A-PTPN3 variations in neuroblastoma: Implications for poor prognosis and relapse. J. Clin. Oncol. 2020, 38 (Suppl. 15), e22512. [CrossRef]

27. Dong, R.; Yang, R.; Zhan, Y.; Lai, H.D.; Ye, C.J.; Yao, X.Y.; Luo, W.Q.; Cheng, X.M.; Miao, J.J.; Wang, J.F.; et al. Single-Cell Characterization of Malignant Phenotypes and Developmental Trajectories of Adrenal Neuroblastoma. Cancer Cell 2020, 38, 716-733.e6. [CrossRef]

28. Lee, L.X.; Li, S.C. Hunting down the dominating subclone of cancer stem cells as a potential new therapeutic target in multiple myeloma: An artificial intelligence perspective. World J. Stem Cells 2020, 12, 706-720. [CrossRef] 